\title{
The Effects of Social Anxiety Perceived by Adolescents on their Peer Relationships and Self-Esteem
}

\author{
Hyejin Jung ${ }^{1)}$, Sung-je $\mathrm{Cho}^{2}$ \\ 청소년이 지각한 사회불안이 또래 관계 및 자아존중감에
미치는 영향 \\ 정혜진1), 조성제2)
}

\begin{abstract}
The purpose of this study is to investigate the effects of the social anxiety perceived by adolescents on their peer relationships and self-esteem. For the study, 132 adolescents in OO-si, Kyeongsangbukdo, were investigated. The collected data were analyzed through frequency analysis, reliability test and correlation analysis on the SPSS program, and also a multiple regression analysis was conducted for the causal relationship between the variables. The results of the analysis were as follows. First, the fear of negative evaluation and the fear of unfamiliar situations, the sub-factors of social anxiety of adolescents, were revealed to have negative influences on their peer relationship. Second, the performance anxiety and the fear of negative evaluation, the sub-factors of social anxiety of adolescents, were revealed to have negative influences on their self-esteem. Such results imply that the more the adolescents fear negative evaluation and unfamiliar situations, which indicate a higher level of social anxiety, the lower their level of self-esteem becomes. This study is considered to provide the foundation data for preparing educational programs that aim to enhance the positive psychological state of adolescents.
\end{abstract}

Keywords: Adolescents, Social Anxiety, Negative Evaluation, Peer Relationship, Self Esteem

$$
\text { 요 약 }
$$

본 연구의 목적은 청소년이 지각한 사회불안이 또래관계 및 자아존중감에 미치는 영향에 대하여 파 악하는 데 있다. 연구대상은 경상북도 $\mathrm{OO}$ 시의 청소년 132명을 설문대상으로 조사하였다. 분석방법은 SPSS 21.0 프로그램을 이용하여 빈도분석과 신뢰도분석을 실시하였으며, 변수 간의 상관분석 및 인과

Received(April 02, 2020), Review Result(1st: May 01, 2020, 2nd: June 17, 2020), Accepted(June 25, 2020)

1) (Ph.D. course/doctorate course) 02838 Dept. of Culture and Art, Dongbang Culture Graduate University, 28 Sungbok-Ro, Sungbokdong, Seoul, Korea

email: jhj8104@naver.com

2) (Professor, Corresponding Author) 02838 Dept. of Culture and Art, Dongbang Culture Graduate University, 28 Sungbok-Ro, Sungbokdong, Seoul, Korea

email: chosj715@daum.net 


\section{The Effects of Social Anxiety Perceived by Adolescents on their Peer Relationships and Self-Esteem}

관계에 대한 다중회귀분석을 실시하였다. 연구결과 첫째, 청소년이 지각한 사회불안의 부정적 평가에 대한 두려움, 낮선 것에 대한 두려움 요인은 또래관계에 부적영향을 미치는 것으로 나타났다. 둘째, 청소년이 지각한 사회불안의 수행불안, 부정적 평가에 대한 두려움 요인은 자아존중감에 부적영향을 미치는 것으로 파악되었다. 이는 청소년이 지각한 사회불안의 부정적 평가에 대한 두려움, 낮선 것에 대한 두려움 요인이 높을수록 또래관계가 낮아지며, 사회불안의 수행불안, 부정적 평가에 대한 두려 움 요인이 높을수록 자아존중감이 낮아진다는 것을 의미하는 것이다. 본 연구는 청소년의 자아존중 감 증진을 위한 교육 프로그램 마련의 정책 자료가 될 것으로 판단된다.

핵심어: 청소년, 사회불안, 또래관계, 자아존중감

\section{1. 서론}

\section{1 연구의 필요성}

최근 의과학 발달과 경제적인 성장으로 점차적으로 생활이 편리해지고 있다. 또한 다양한 변화와 미디어의 영향으로 공동체적인 사회는 자기중심적이며, 폐쇄적인 문제로 새로운 현장으로 대두되 고 있다. 따라서 청소년이 지각하는 사회불안은 또래 관계 및 자아존중감에 미치는 영향은 어떠한 지가 중요한 요소로 나타나고 있다. 특히 청소년기는 아동기에서 성인기에 이르는 과도기이며 신 체적, 정서적, 도덕적, 사회적 불안들이 활발하게 이루어지는 시기라고 할 수 있다. 먼저 청소년기 에 중요한 영향을 미치는 또래관계의 개념을 확인해 보면 "상호작용을 하기 위해 행동할 때 복잡 한 수준이 비슷하고 친근한 동등한 지위를 가진 구성원들로, 서로 간에 심리적 관계 집단을 또래 관계로 말하며, 또래관계는 서로 또래 간의 상호관계를 나타내며, 수평적인 구조를 형성하는 것을 말한다"[1].

선행연구를 통하여 살펴보면, 아동과 청소년을 대상으로 하여 또래를 좋아하는 이유와 싫어하는 이유가 연령에 따라 변화하는지를 탐색하면, '어릴 때는 또래와의 놀이, 교제, 관심이 또래를 좋아 하는 이유였다면, 청소년기에는 자신과 생각이 같고 믿을 수 있는 또래를 좋아하여 신뢰와 비밀 공유가 친한 또래를 결정하는 요인'이었다. 그리고 또한 '대학생은 진실성, 친밀, 유사성에 따라 또 래를 결정하였으며 이러한 결과는 또래관계가 연령에 따라 점차 다르게 형성되고 발달한다고 하 였다[2].

특히, “개인 또는 두 명의 또래와 친밀한 관계를 형성하며 영향을 주고받는 관계는 구성원의 흥 미와 관심에 의하여 자극을 받을 수 있으며, 친한 또래친구와 우정을 나누면서 '응집성', '통합성', '위계와 지배', ‘이질성', '집단규범', ‘충성심', '갈등해결방법'도 알 수 있다. 특히 또래와 일대일로 친한 관계를 유지하려면 더 많은 노력이 필요함으로 쉬운 일은 아니다[3].

따라서 청소년은 "다양한 관계를 통해 타인과 함께 적응하며 살아가는 방법을 배우며, 사회에 적응한다고 볼 수 있다. 이 시기에는 경험하는 인간관계는 이 시기뿐 아니라 전생애를 통해 영향 을 미칠 수 있다. 타인과의 효과적인 관계를 위한 상호작용을 하는 사회적 기술이 필요하다. 이는 청소년에게 사회기술을 가장 중요한 구성 자원이라 할 수 있는 또래관계기술“ 이라고 하였다[4]. 
자아존중감에 대하여 살펴보면, 자신을 가치있고 또한 긍정적인 존재로 인식하며, 자기 역량 강 화를 구성하는 요인으로, 이와 관련된 선행 연구를 살펴보면 자아라는 개념은 James가 처음으로 사용하기 시작하였다. James는 자아는 "자신이 자신의 것이라고 부를 수 있는 모든 것"이라고 정 의하면서 자신의 신체, 특성, 능력, 가족, 친구, 직업 등 자신과 관련된 모든 것을 포함한다고 했다 [5]. 즉 자아존중감을 자아의 긍정적 또는 부정적 태도에 대한 주관적인 평가라고[6]하였다.

Rosenburg[7]는 자기신념과 자아존중감을 구분하였고, 자기신념은 Bandura[8]의 "자기효능감의 개념과 관계되는 것으로서 장애를 극복하고 새로운 도전에 직면하는 자아와 그러한 환경을 조절하 는 의미"라고 정의하였고, “자아존중감은 자신의 자아를 수용하며 자아의 가치를 느끼는 정서적인 의미"라고 주장하였다. 그리고 자아존중감은 자신이 유능하고 중요한 존재이며 성공할 수 있고 가 치 있는 인간으로 인식하는 정도라고 정의하면서 자기신념과 자아존중감은 엄밀히 다른 개념임을 설명하였다.

국내 학자들의 자아존중감에 개념에 대한 연구를 살펴보면, 자아존중감은 학자에 따라 자아정체 성, 자아존중, 자기인식 등 개념과 혼용하여 사용[9]하고 있으며, 이현우(2012)는 '자아개념의 평가 요소로 자신의 평가에서 긍정적으로 수용하고 스스로 가치 있는 인간으로 여기는 것을 자아존중 감이라 하였다[10]. 또한 청소년을 대상으로 '부모-자녀 상호작용과 인터넷 게임중독의 사이에서 자아존중감이 매개효과가 있는 것'으로 검증되었다. 즉 부모-자녀 상호작용과 인터넷 게임중독 간 에서는 자아존중감이 간접적으로 효과적이라고 볼 수 있다[11].

이러한 선행연구 결과를 통해 학교 부적응 청소년이 지각하는 사회불안이 또래 관계 및 자아존 중감에 미치는 영향에 대한 연구의 필요성이 대두된다. 연구자와 선행연구의 공통점을 살펴보면 기존 연구에서는 청소년을 대상으로 학교 부적응 및 또래 관계 형성에 대한 연구가 일부 진행되었 지만 청소년을 대상으로 또래 관계 및 자아존중감에 대한 연구는 미흡한 실정이다. 따라서 차이점 을 살펴보면 본 연구에서는 학교 부적응 청소년의 지각하는 사회불안이 또래 관계 및 자아존중감 에 미치는 영향을 밝힘으로써 위기 및 학교 부적응의 비행청소년의 급증하는 시대적인 문제를 해 결하기 위해 청소년의 우울과 스트레스, 심리적 불안감 예방에 대한 기초자료를 제공하고자 한다.

\section{2 연구문제}

본 연구의 목적은 인생의 과도기적인 시기의 청소년이 지각하는 사회불안이 또래관계 및 자아존중 감에 미치는 영향에 대하여 분석하는 데 있다. 이에 대한 연구문제는 다음과 같다.

첫째, 학교 부적응 청소년이 지각한 사회불안이 또래관계에 미치는 영향은 어떠한가?

둘째, 학교 부적응 청소년이 지각한 사회불안이 자아존중감에 미치는 영향은 어떠한가? 


\section{2. 연구방법}

\section{1 연구대상}

본 연구는 2019년 3월 10일부터 2018년 5월 10일까지 경상북도 00시의 청소년을 대상으로 조사하 였다. 설문조사는 설문대상자에게 설문내용을 상세히 설명한 후 설문을 수행하였다. 설문조사를 총 140 부의 수집한 후 불성실한 설문지 8 부를 제외한 132 부의 통계자료에 적용하였다.

\section{2 연구도구}

본 연구에 사용된 도구는 인구사회학적 특성 4 문항, 사회불안 40 문항, 자아존중감 21 문항으로 구성 되어 있다. 인구사회학적 특성에 관한 내용은 성별, 학년, 종교유무, 부모 교육정도 등으로 구성하 여 조사하였다. 청소년의 사회불안을 측정하기 위해 유선미[12]가 사용한 사회불안의 측정도구는 하위요인 수행불안 10 문항, 부정적 평가에 대한 두려움 9 문항, 회피 행동 및 사고 9 문항, 낮선 것 에 대한 두려움 5 문항, 비주장성 7 문항으로 설계하였다. 각 설문문항은 리커트 5 점 척도로 구성하 였다. 청소년의 또래관계를 측정하기 위해 진원식[13]이 사용한 또래관계 측정도구는 하위요인 신 뢰 9문항, 의사소통 9문항, 화 및 소외감 6 문항으로 설계하였다. 각 설문문항은 리커트 5 점 척도로 구성하였다. 청소년의 자아존중감을 측정하기 위해 김신자[14]가 사용한 자아존중감 측정도구는 하 위요인 일반적 자아 6 문항, 사회적 자아 9 문항, 집중감 4 문항, 가정에서의 자아 9 문항, 학교에서의 자아 8문항으로 설계하였다. 각 설문문항은 리커트 5점 척도로 구성하였다.

\section{3 신뢰도}

본 연구에 사용된 각 변수의 신뢰도 검증결과 사회불안 .980, 또래관계 .929, 자아존중감 .742 의 신 뢰도를 보이고 있다. 각 측정도구의 신뢰도는 Cronbach's a값이 모두 .60이상으로 신뢰성을 확보하 였다. 신뢰도 분석결과는 [표 1]과 같이 나타났다.

[표 1] 주요 변수의 신뢰도

[Table 1] Reliability of Key Variables

\begin{tabular}{ccc}
\hline 구분 & 문항수 & Cronbach's $\alpha$ \\
\hline 사회불안 & 40 & .980 \\
또래관계 & 24 & .929 \\
자아존중감 & 21 & .742 \\
\hline
\end{tabular}




\section{4 자료처리 및 분석방법}

연구에 수집된 자료처리는 SPSS 21.0 프로그램을 사용하여 통계처리를 하였다. 통계처리의 유의수 준은 $5 \%$ 에서 검증하였다. 청소년의 인구사회학적 특성은 빈도 분석을 실시하였다. 청소년의 사회 불안, 또래관계, 자아존중감에 대한 상관분석을 하였고, 인과관계를 분석하기 위하여 다중회귀분석 을 실시하였다.

\section{3. 연구결과}

\section{1 인구사회학적 특성}

본 연구대상자의 인구사회학적 특성을 살펴보면, 청소년의 성별은 남자 63 명 $(47.7 \%)$, 여자 69 명 (52.3\%)으로 나타났다. 학년은 고3이 48 명(36.4\%)으로 가장 많았으며, 고2가 44 명 $(33.3 \%)$, 고1이 40 명(30.3\%) 순으로 조사되었다. 종교유무는 무 84명(63.6\%), 유 48명(36.4\%)으로 종교가 있는 학생보 다 종교가 없는 학생이 훨씬 더 많은 것으로 나타났다. 부모 교육정도를 살펴보면, 대졸이 91명 $(68.9 \%)$ 로 가장 많았으며, 고졸 22명 $(16.7 \%)$, 대학원졸 19 명 $(14.4 \%)$ 순으로 조사되었다.

\section{2 주요 변수에 대한 기술통계}

\subsection{1 사회불안에 대한 기술통계}

청소년의 사회불안에 대한 측정 변수는 5 점 척도로 측정하였다. 사회불안의 하위요인별로 살펴보 면, 수행불안(M=3.52) 요인이 가장 높게 나타났으며, 부정적 평가에 대한 두려움( $\mathrm{M}=3.48)$, 낮선 것 에 대한 두려움 $(\mathrm{M}=3.36)$, 비주장성 $(\mathrm{M}=3.26)$, 회피 행동 및 사고( $\mathrm{M}=3.23)$ 순으로 모두 평균점수 이 상으로 나타났다.

\subsection{2 또래관계에 대한 기술통계}

청소년의 또래관계에 대한 측정 변수는 5 점 척도로 측정하였다. 또래관계의 하위요인별로 살펴보 면, 신뢰 $(\mathrm{M}=3.18)$ 요인이 가장 높게 나타났으며, 의사소통 $(\mathrm{M}=2.92)$, 화 및 소외감 $(\mathrm{M}=2.91)$ 순으로 모두 평균점수 이상으로 나타났다. 청소년의 또래관계에 대한 기술통계를 살펴본 결과는 [표 2]와 같다. 
[표 2] 또래관계에 대한 기술통계

[Table 2] Descriptive Statistics on Peer Relationships

\begin{tabular}{ccccccc}
\hline & 구분 & $\mathrm{N}$ & 최소값 & 최대값 & $\mathrm{M}$ & $\mathrm{SD}$ \\
\hline \multirow{4}{*}{ 또래관계 } & 신뢰 & 132 & 1.00 & 5.00 & 3.18 & .93 \\
& 의사소통 & 132 & 1.00 & 5.00 & 2.92 & .98 \\
& 화 및 소외감 & 132 & 1.00 & 4.33 & 2.91 & .74 \\
& 전체 & 132 & 1.00 & 4.78 & 3.00 & .83 \\
\hline
\end{tabular}

\subsection{3 자아존중감에 대한 기술통계}

청소년의 자아존중감에 대한 측정 변수는 5 점 척도로 측정하였다. 자아존중감의 하위요인별로 살 펴보면, 일반적 자아 $(\mathrm{M}=3.22)$ 요인이 가장 높게 나타났으며, 학교에서의 자아 $(\mathrm{M}=3.05)$, 가정에서의 자아 $(\mathrm{M}=2.76)$ 순으로 평균점수 이상으로 나타났다. 한편 사회적 자아 $(\mathrm{M}=2.37)$ 요인은 평균점수보다 낮게 나타난 것을 알 수 있다. 청소년의 자아존중감에 대한 기술통계를 살펴본 결과는 [표 3]와 같 다.

[표 3] 자아존중감에 대한 기술통계

[Table 3] Descriptive Statistics on Self-respect

\begin{tabular}{|c|c|c|c|c|c|c|}
\hline & 구분 & $\mathrm{N}$ & 최소값 & 최대값 & M & SD \\
\hline \multirow{5}{*}{ 자아존중감 } & 일반적 자아 & 132 & 1.00 & 5.00 & 3.22 & .78 \\
\hline & 사회적 자아 & 132 & 1.00 & 5.00 & 2.37 & 1.05 \\
\hline & 가정에서의 자아 & 132 & 1.00 & 5.00 & 2.76 & 1.01 \\
\hline & 학교에서의 자아 & 132 & 1.50 & 4.75 & 3.05 & .47 \\
\hline & 전체 & 132 & 1.51 & 4.63 & 2.85 & .64 \\
\hline
\end{tabular}

\section{3 변수 간의 상관관계}

청소년이 지각하는 사회불안, 또래관계, 자아존중감과의 관련성을 살펴본 결과, 청소년이 지각하는 사회불안과 또래관계는 높은 수준의 음의 상관관계를 지니는 것으로 확인되었다 $(\mathrm{r}=-.813, \mathrm{p}<.01)$. 사회불안과 자아존중감 요인도 높은 수준의 음의 상관관계를 지니고 있음을 알 수 있다(r=-.862, $\mathrm{p}<.01)$. 한편, 또래관계 요인과 자아존중감 요인은 높은 수준의 양의 상관관계를 지니는 것으로 나 타났다 $(\mathrm{r}=.836, \mathrm{p}<.01)$. 각 변수 간의 상관분석결과는 [표 4]과 같이 나타났다. 
[표 4] 주요 변수 간의 상관관계

[Table 4] Correlation between Key Variables

\begin{tabular}{cccc}
\hline 구분 & 사회불안 & 또래관계 & 자아존중감 \\
\hline 사회불안 & 1 & & \\
또래관계 & $-.813^{* *}$ & 1 & 1 \\
자아존중감 & $-.862^{* *}$ & $.836^{* *}$ & 1 \\
\hline
\end{tabular}

${ }^{*} \mathrm{p}<.05,{ }^{* *} \mathrm{p}<.01$

\section{4 청소년의 사회불안이 또래관계 및 자아존중감에 미치는 영향}

\subsection{1 청소년이 지각한 사회불안이 또래관계에 미치는 영향}

청소년이 지각한 사회불안이 또래관계에 미치는 영향을 알아보기 위하여 다중회귀분석을 실시하였 다. 분석결과, 또래관계에 대한 사회불안 요인의 설명력을 의미하는 $\mathrm{R}^{2}$ 값이 .678로 나타나 전체 변 동의 $67.8 \%$ 로 회귀모형을 설명하고 있다. 사회불안의 하위요인별로 영향력을 살펴보면, 부정적 평 가에 대한 두려움( $\beta=-.423, \mathrm{p}<.01)$, 낮선 것에 대한 두려움( $\beta=-.417, \mathrm{p}<.05)$ 은 또래관계에 부적(-) 영 향을 미치는 것으로 나타났다. 반면, 사회불안의 하위요인 수행불안( $\beta=-.233, p>.05)$, 회피 행동 및 사고 $(\beta=.102, \mathrm{p}>.05)$, 비주장성 $(\beta=.121, \mathrm{p}>.05)$ 요인은 또래관계에 영향을 미치지 않았다. 이는 청소 년이 지각한 사회불안의 부정적 평가에 대한 두려움, 낮선 것에 대한 두려움 요인이 높을수록 자 아존중감이 낮아진다는 것을 의미하는 것이다.

\section{4 .2 사회불안이 자아존중감에 미치는 영향}

청소년이 지각한 사회불안이 자아존중감에 미치는 영향을 알아보기 위하여 다중회귀분석을 실시하 였다. 분석결과, 자아존중감에 대한 사회불안 요인의 설명력을 의미하는 R2값이 .777로 나타나 전 체 변동의 $77.7 \%$ 로 회귀모형을 설명하고 있다. 모형에 대한 분산분석 결과 추정된 회귀모형 $(\mathrm{F}=87.794, \mathrm{p}<.000)$ 은 통계적으로 유의미한 것으로 나타났다. 사회불안의 하위요인별로 영향력을 살 펴보면, 수행불안( $\beta=-.522, \mathrm{p}<.01)$, 부정적 평가에 대한 두려움 $(\beta=-.606, \mathrm{p}<.01)$ 은 자아존중감에 부적 (-) 영향을 미치는 것으로 나타났다. 반면, 사회불안의 하위요인 회피 행동 및 사고( $\beta=-.032, p>.05)$, 낮선 것에 대한 두려움( $\beta=-.02, \mathrm{p}>.05)$, 비주장성 $(\beta=.232, \mathrm{p}>.05)$ 요인은 자아존중감에 영향을 미치 지 않았다. 이는 청소년이 지각한 사회불안의 수행불안, 부정적 평가에 대한 두려움 요인이 높을수 록 자아존중감이 낮아진다는 것을 의미하는 것이다. 


\section{4. 결론 및 제언}

본 연구에서는 청소년이 지각한 사회불안이 자아존중감에 미치는 영향에 대하여 분석하였다. 분석 결과를 토대로 구체적으로 논의하면 다음과 같다.

첫째, 청소년이 지각한 사회불안이 또래관계에 미치는 영향관계를 분석한 결과, 사회불안의 하 위요인 중 부정적 평가에 대한 두려움, 낮선 것에 대한 두려움 요인은 또래관계에 부적으로 유의 한 영향을 미치는 것으로 나타났다. 반면, 사회불안의 하위요인 수행불안, 회피 행동 및 사고, 비주 장성 요인은 또래관계에 유의한 영향을 미치지 않는 것으로 나타났다. 이는 청소년이 지각한 사회 불안의 부정적 평가에 대한 두려움, 낮선 것에 대한 두려움 요인이 높을수록 또래관계가 낮아진다 는 것을 의미하는 것이다.

둘째, 청소년이 지각한 사회불안이 자아존중감에 미치는 영향관계를 분석한 결과, 사회불안의 하위요인 중 수행불안, 부정적 평가에 대한 두려움 요인은 자아존중감에 부적으로 유의한 영향을 미치는 것으로 나타났다. 반면, 사회불안의 하위요인 회피 행동 및 사고, 낯선 것에 대한 두려움, 비주장성 요인은 자아존중감에 유의한 영향을 미치지 않는 것으로 나타났다. 이는 청소년이 지각 한 사회불안의 수행불안, 부정적 평가에 대한 두려움 요인이 높을수록 자아존중감이 낮아진다는 것을 의미하는 것이다. 따라서 가정과 사회와 교육과정에서 학교 부적응 청소년이 심리적 안정감 을 느끼며 적응할 수 있는 환경적 여건이 턱 없이 부족한 부분을 개선적으로 살펴보아야 한다.

이상의 논의된 바와 같이 향후 청소년의 심리적 안정감이 향상 될 수 있도록 교육현장에서의 실천적 개입 방안 마련을 위한 구체적인 연구가 필요하다.

\section{References}

[1] Harter, S., The perceived competence scale for children, Child Development, (1982), Vol.53, No.1, pp.87-97.

[2] Hwang, Hye-jung, The Development of Friendships in Children and Adolescents, Korean Journal of Child Studies, (2002), Vol.23, No.3, pp.35-49.

[3] Moon, Moo-kyung, Understanding of learning and development-focusing on peer relationships, Koea Seoul: Changjisa, ISBN, 8942602509, 9788942602506, (2005)

[4] Caldarella, P., Merrell, K. W., Common dimensions of social skills of children and adolescents: A taxonomy of positive behaviors, School Psychology Review, (1997), Vol.26, No.2, pp.264-278

[5] James, W., The principles of psychology, USA: Henry Holt and Company, (1890).

[6] Rosenberg, M., Rosenberg self-esteem scale (SES), Society and the adolescent self-image, USA: Princeton University Press, (1965) 
[7] Rosenburg, M., Conceiving the self, USA New York: Basic Books, (1979)

[8] Bandura, A., Self-efficacy: toward a unifying theory of behavioral change, Psychological Review, (1977), Vol.84, No.2, p.191-215.

[9] Lee Kyoung Hee, The Relationship of Emotional Regulation Strategies and School Adjustment in Junior High School Students, Journal of Home Economics Education Research, (2009), Vol.21, No.2, pp.159-169.

[10] Lee, Hyunwoo, A study of self-esteem, social support, and mental health of the elderly in a nursing home, Seoul Hanyoung University, Doctorial Dissertation, (2012)

[11] Choon Bum Cho, Jinseop Lim, Parent-Child Interaction and Internet Games Addiction and Delinquency in adolescence: The Role of Self-esteem as Mediators, Korean Journal of Youth Studies, (2010), Vol.17, No.9, pp.197-226.

[12] S. M. You, Cognitive Behavioral Therapy focusing on Cognitive Process Enhancement for Adolescents with Social Anxiety Disorder, Myongji University, Doctorial Dissertation, (2018)

[13] S. W. Jin, A Study on Effect of Degree of Using Smartphone by Middle School Students on the Self-esteem, Peer Relationship and Parental Relationship, Kukje Theological University and Seminary, Doctorial Dissertation, (2018)

[14] S. J. Kim, The Effects of Tealife Education Program on Children's Self-esteem and Sociality, Mokpo National University, Doctorial Dissertation, (2019) 